\title{
Class climate: the views of adult students in evening schools
}

\author{
Dr. Vasiliki Brinia ${ }^{1}$, Ioannis Michaelidis ${ }^{2}$ \\ ${ }^{1,2}$ Hellenic Open University, Patra, Greece
}

\begin{abstract}
The purpose of this research is to investigate adult students' views in Evening Vocational High Schools and in Evening General High Schools, regarding the learning process, the quality of relationship between teachers and adult students and the interaction between the adult students. The research collected quantitative data via questionnaire. The sample consisted of 90 adult learners from 4 high schools of the Greek region Achaia. The results showed that the vast majority of adult students agree that the climate among classmates is friendly and cooperative. They also tend to agree that the coexistence of different ages in a classroom is creative. Moreover, a large portion of the students states that teachers use participatory techniques in the learning process and treat them as equals. However, they would wish to see more interactive methods of teaching that would encourage active participation and collaboration in groups. These goals can be achieved by organizing training seminars to improve their teachers' communication skills and their educational methodology and techniques.
\end{abstract}

Keywords: adult students, Evening High Schools, classroom climate

\section{Introduction}

Evening high schools have the particularity that students who attend are adults and underage. Despite the fact that most of their students are adults, these schools are part of the secondary (formal) education and they are not part of adult education. Previous research in education of evening schools focused on the profile of students attending these schools or the implementation of participatory educational techniques exploring mainly the views of teachers of evening schools. Most of them are not conducted in Second Chance Schools and in evening high schools. In this research, we focused on mapping the learning environment and the quality of interpersonal relations in the evening high schools through the eyes of their protagonists, namely adult students. The reason we were selected the evening high schools is that they are part of the post-compulsory education, which has two meanings:

a) The trainees have consciously decided for different reasons to attend a training step aimed at "providing general education of high level" (as stated in the objectives of general high school), devoting the major part of their evening for four years.

b) In this level of education the curriculum dominates the learning process as it prepares the students for the national exams at the end of four years of study, thus affecting the teachers and the teaching methods.

\section{Theoretical Part}

\section{Adult education}

Rogers (1999) notes the specific characteristics of the adults as learners. Specifically:

- They are all adults, meaning they already are in an ongoing maturity process, so their education should encourage this development of self-fulfillment, perspective and autonomy. An educational process which treats the adults as children, would create barriers to learning.

- They have specific objectives, like professional or personal development, acquisition and prestige.

- They bring a set of experiences and values, rooted prejudices and attitudes in which they invest emotionally. So they perceive everything through the prism of the experience and knowledge they already have.

- They prefer the content of the courses and training to be linked and built upon their experiences. The utilization of experiences as the starting point for new knowledge is a key chapter of adult learning. When this experience is ignored by the educator, adults perceive it as rejecting the person himself/herself and not just his/her experience.

- They already know their preferred ways of learning through various learning activities in which they were involved in the previous years.

- They tend to actively participate in the learning process. The real interest in learning stems from the relationship between the learner and the learning object. The interests of the learner are the result of experience and the familiarity with an activity tends to make it dear (Noye \& Piveteau, 1999: 104). 


\section{Prerequisites for effective adult learning}

Kokkos (2008) suggests a number of basic conditions which are basic for effective adult learning and can be summarized as follows:

a) The training is voluntary. The pressure on adults to participate in the educational process in most cases act as a deterrent.

b) The educational objectives must be clear. The objectives should be as realistic as possible, connected to the students' needs and the objective needs of professional and social environment.

c) The course should be organized at all levels, such as logistics, training materials and office support.

d) The content must be directly related to the needs and experiences of learners. The issues addressed should be related to the situations that are faced or will be faced by the students, and their experiences should be used. (Usher, 1997, ref. in Illeris, 2009: 171).

e) The preferred learning styles should be taken into account. The organization of teaching process must take into account the ways in which each student learns best, the diagnosis of which can be done through systematic observation by the educator.

f) Active participation in the educational process should be encouraged. Depending on the learning group the instructor should allow more initiative and should motivate the learners to participate actively in the learning process

g) The barriers to learning which are faced by each student individually, as well as ways to overcome them should be explored.

h) The learning climate should be characterized by effective communication, collaborative spirit and mutual respect. Such a climate is essential in order for the other conditions to be achieved.

i) The educator is not carrier of knowledge but a coordinator and a catalyst of the learning process.

\section{Interpersonal relationships between teachers-students}

Teaching adults is not only a set of techniques and methods, but also it is a process of exchanging thoughts and experiences in an atmosphere of friendliness and support, so that participants will feel secure and the pedagogical relationship will be developed.The climate of class or learning environment is defined as the special atmosphere created in a class within the interactive relationships between educators and students (Borich, 1999, ref. in Mparalos \& Photopoulou). The learning environment reflects a grid of cultural, social, institutional and psychological variables. These interact in complex ways to produce a unique pattern of events, habits, opinions and learning style that overwhelms the learning process (Boud \& Walker, 1994). Creemers and Reezigt (2003, ref. in Mparalos \& Fotopoulou) distinguish the following four dimensions of the class's climate:

1) Natural environment (size, location within the school etc)

2) Social system (relationships and interaction between students teachers and students)

3) Organized classroom environment (arrangement of space, comfort etc.)

4) Expectations of teachers for the learning outcomes of their students (positive expectations, feelings of selfefficacy).

Interpersonal relationships between teachers and students determine the level of support provided by the teacher to the students, the involvement of students in the educational process and their inclusion in the social class system (Mparalos \& Fotopoulou).

Kokkos (1998: 61-76) analyzes the elements that constitute the process of communication, which are:

- The clarity and completeness of the messages are important for the success of the communication.

- Verbal and non-verbal messages.

- The way in which reality is perceived. Everyone has a perception based system which help us understands reality in a subjective manner. The sincere effort to understand other people equally and regardless of the hierarchical position is a constructive attitude towards communication. Understanding is not the uncritical acceptance of the views of others, but a process in which after listening carefully to the arguments, we review a situation, we may change some of our own stereotypes, and adopt the views of the others.

- The context of communication.

- The importance of emotions. The externalization of feelings is necessary in order to develop interpersonal communication. We need to learn how to familiarize ourselves with our feelings and we then express them in comfort. Recent studies on transformative learning reveal that aspects such as emotion, intuition, soul, spirituality and body are integral to the deep and significant process towards change (Dirkx, 2001).

- The two levels of messages: the level of the information and the level of the relationship between transmitter and receiver.

- Self-esteem and mutual respect are key elements in communication.

According to Courau (1994: 101) the creation of a friendly climate, the management of the relationships and the motivation of the team are the details that the participants in a program often remember more. Additionally, he claims that in order to achieve the objectives in some educational programs tension and 
conflict are inevitable. In order for the educators to succeed they must use appropriate motivational techniques and understand the phenomena that occur in the group (group dynamics). The interest of adult educators on how the groups work stems from the belief that learning through the groups helps to understand many of the principles of adult education. The groups promote self-understanding through support and mutual feedback. They are the basis for empirical learning, they encourage interaction, promote confidence, bring into question the traditional relationship of the teacher with the students and ultimately these can lead to "learning to learn" (Tennant, 1997).

\section{Evening education}

Katsikas (2016) in an article for the student dropout in the school year 2014-2015, claims that "the dropout is one of the most painful forms of inequality, poverty, abandonment, marginalization and social exclusion sections of the population, a reflection of the division of society into classes". Approximately 5000 children leave high school annually. Children whose parents are unemployed, poor workers or peasants, repatriated, immigrants etc. face the threat of social exclusion. The evening education is called to bear the role of the mediator offering the same opportunities in education. The role of the evening training is to offer educational opportunities to people who are not able to join in the educational process but they wish to acquire knowledge, complete the secondary education, continue their studies at higher educational levels and just acquire knowledge and skills which are necessary for the improvement of their working and social situation (Galitis, 2008).As shown by statistical tables for Secondary Education, in the school year 2014-15, 5656 students attended the General Public Evening Schools in a total of 225.875 students of General Public High Schools. In the Technical Evening Public High Schools 14702 pupils attended in a total of 86.916 students of Technical Public High Schools. Additionally, only 2.5\% of students in Public High Schools are students in Evening Public High Schools and a significant proportion of Public Technical Education, 17\% is held by the Evening Public Technical Education. "It is clear that many students of Technical Education are workers coming from lower and middle economic classes" (Andrianopoulitis, 2016).

Research on the social background of students in the evening schools (Rousseas 1992) comes to the conclusion that the latter come from low socioeconomic status families. Younger students in General Public Evening Schools mentioned as reasons for their diversion from the morning education (Ruse 1993, ref.in Galitis 2005):

a) the need for work,

b) low school performance,

c) emergencies and different circumstances such as expulsion from the school they attended., death of parent, etc.

d) psychosocial factors in the family of the student (daunting climate, lack of acceptance, etc.),

e) the discouragement by some parents (children with low performance) for the prospects of education who urged them start working.

The same research (Ruse 1993, ref, in Galitis 2005) explored the most important reasons of studying in General Public Evening Schools:

a) the convenient hours ( $93 \%)$,

b) high school diploma ( $88.4 \%)$,

c) good student-teacher relations $(57.9 \%)$.

d) high school diploma for getting hired to the public sector (38.3\%),

e) old age $(38.1 \%)$

f) low demands of teachers $(37.2 \%)$.

g) university diploma (26.7\%).

Students who attend evening schools have mostly a long educational history of failures and rejections in morning Elementary and Secondary Schools (Vakali and Vakali, 2009). Therefore, it is obvious that these schools enable integration of both the compulsory and post-compulsory secondary education.

\section{Research Part \\ Methodology}

The purpose of the research is to examine to what extent the education of adult students in evening schools approaching the theoretical framework of adult education, meaning if adult students are treated as such in evening schools. The aim of the research is to explore the views of adult students on the organization of the learning process but also on the quality of relationships between teacher and learner and among the learners themselves. To achieve the goals we set the following research questions:

1) What are the views of adult students regarding the organizing the learning process.

2) What are the views of adult students regarding their relationship with their teachers.

3) What are the views of adult students regarding their relationship with their classmates. 
We chose the quantitative research and we used a questionnaire in order to record the attitudes and opinions of adult students regarding the learning environment and the quality of relationships in the school. The choice of the questionnaire as a tool allows to collect data in a short time and to address a larger sample size (Creswell, 2011). The questionnaire includes closed-ended questions which use the five-point Likert scale $(1=$ strongly agree, 2 = agree, $3=$ neutral, $4=$ disagree, $5=$ strongly disagree) and an open-ended question. The data was analyzed with the program SPSS 22.

The target population is adults students attending Evening High Schools of the Greek region Achaia. The choice of schools was based on the distance from the place of residence and work of the researcher. Therefore, the sampling may be characterized as "convenient" (Creswell, 2011).

We sent 120 questionnaires in four evening schools, two GEL and 2 EPAL. The final sample was 90 students, of which 58 (64.4\%) were male, and 32 (35.6\%) women.

Regarding the structure of the questionnaire is consists of four sectors:

1) Demographic data: Seven closed-ended questions about gender, age, class, years of attendance at evening schools, as well as a question on how they were informed about the evening high school.

2) Relationships with peers: 14 closed-ended questions with five-point Likert scale $(5=$ strongly agree, $4=$ agree, 3 = neutral, 2 = disagree $1=$ strongly disagree) and an open-question. The questions explored the views of adult students on:

a) the interaction they have with their younger peers,

b) the emotional fulfillment by communication with peers,

c) the sense of participation in the learning group,

d) the creation of social relations,

e) any peer attitudes that are annoying.

3) Relationships with teachers: 16 closed-ended questions and one open-ended about the views of students on the characteristics of the role of teachers, compared to how they are defined in the adult education.

4) Organization of the learning process: 23 closed-ended questions and one open-ended regarding:

a) how the course is organized,

b) how they would like for the course to be organized

c) the reasons why they have difficulty to understand a subject.

\section{Relationships with peers}

\section{Findings - Discussion}

The majority of respondents $(73.3 \%)$ agrees that there is a climate of cooperation with peers in the classroom. A very large proportion $(82.5 \%)$ of the age group $25+$ agrees that they receive support and encouragement by their peers when they face difficulties. However, there is a significant disparity in the age group of $18-24$ as only $62.9 \%$ agrees to that. When a team works, sometimes the members feel that they can communicate their feelings, intentions and purposes. This cohesion in the group has deep educational impact in learning and social behavior, because members feel less alone in their problems, more connected, more in harmony with others, more ready to cooperate and strive for common goals (Gournas, 2012). Social relations in the classroom affect whether students feel pleasure in the class. The satisfaction from their participation in the class has a direct impact on their performance, but also in general mental state (Mpikos, 2004).

The existence of subgroups (cliques) that prevent the cohesion of the group is presented by $38.5 \%$ of students in the age group 18-24 and 27.4\% of students in the age group 25+. According to Mpikos (2004) the existence of these subgroups, which are called friendly cliques are normal and expected mainly due to the inability of people to interact so closely with many others. The presence of subgroups becomes problematic for the coexistence in the classroom when the reasons for setting them up is the dissatisfaction with the involvement in the learning process. As a consequence, goals of the clique conflict with the goals of the class. A big problem created by the main feature of the clique is the high cohesion of its members, which creates barriers in communication and even rejection for classmates with different characteristics (cultural, social, etc.). From the answers, we observe that older students have more positive relationships with their peers and they believe that the class climate is more collaborative.

Regarding the interaction between adults and younger students, the coexistence of underage and adult learners is perhaps the most important particularity of evening schools. About half of adult students consider that both themselves and the younger students benefit from their coexistence in the classroom. A large percentage $(70 \%)$ considers the relationship with peers of different ages constructive and that relations with younger students is feasible and in the process they become better (agrees 78.9\%). It also seems that the age group of older adult learners is more bothered by the noise caused in the course by students (39.7\% vs. $14.8 \%)$. Similar are the results of the research by the Zounta (2013) for students of evening Gymnasium with interviews in which underage students find that they do not have common interests with their older peers who are more serious about learning, they want to learn and there is a lack of communication. But they admit that older 
classmates help with their behavior and their experience as they are a positive influence; they understand, protect and encourage. A small percentage (19.1\%) of the two age groups considers that the age heterogeneity has a negative impact on interpersonal relations, while $77.7 \%$ felt that the evening school offers opportunities for meaningful social interaction. In the research of Galitis (2011) in evening school graduates, $87.9 \%$ of respondents felt that attending the evening school offered socializing opportunities, while $50 \%$ reported that they created social contacts with people of different ages and obligations. Furthermore, 54.8\% think that the evening school offered cultural awareness opportunities, particularly through cultural events of the school, while $75 \%$ thought that after graduation they better understand the content of cultural events, and are now interested in attending cultural events (Galitis, 2011).

The enthusiasm for participation in school events or programs is more obvious in older students ( $73 \%$ vs. $48.1 \%$ of younger). This agrees with the theoretical framework of adult education, as one the characteristics of adult learners is their desire for active participation in their educational experience. What bothers more the older students in the classroom is mostly the fuss and indifference on the part of some classmates. The older students often interfere (in a gentle way, a single nod from the side) to restore "order" when the younger cross the boundaries, helping the teacher (Tsikalaki, 2006). Antagonism seems to be on a smaller scale at evening schools and this is positive because "competition within the school downgrades relationships, so the weak students become inactive and passive recipients during their communication with the teacher and their peers" (Zergiotis, 2007: 9).

\section{Relationships with the teachers}

The answers are classified regarding the roles of the educator in adult education:

- The role of the coordinator: They inform their students about the objectives of the course (76.4\%). Teachers use the students' experiences in order to build new knowledge (70.8\%).

- The role of learning guide: The teachers try to adapt the course to the students' abilities and learning styles (76.4\%), they devote time to listen to students' views and to answer to their questions (82\%).

- The role of supporter: A very large percentage $(95.4 \%)$ considers that they are supported by teachers in order to have active participation in the course. Additionally, teachers use praise and reward (83.1\%), they show understanding because of their increased obligations (91.9\% of the 25+ age group, and 55.5\% of age group 18 to 24). Almost all individuals (95.1\%) of age group 25+ agree that they are encouraged by their teachers to participate in the course (66.6\% for age group 18-24).

- The role of mediator between the students and the learning object through organized activities: Teachers use different techniques during their teaching (70.7\%), they do not use tiring and long presentations $(61.8 \%)$, they want for their students to understand the new knowledge and, thus, they do not hurry to finish the course (43.8\% agree, $31.5 \%$ are undecided), they use new technologies or other teaching equipment in class $(40.4 \%$ agree, $37.1 \%$ are undecided).

- The role of the catalyst in creating a positive climate: Teachers promote interpersonal relationships among students $(69.6 \%$ ), while adult learners are treated equally (agrees $91.8 \%$ of the $25+$ group, and $62.9 \%$ of the 18-24 group).

$59.7 \%$ of the $25+$ age group prefer teachers with communication skills rather than teachers with scientific training, while the proportion of the age group 18-24 is $74 \%$. In the open-ended question regarding the features in the behavior of teachers that attract them, the students claim: to be patient, show appreciation to their students, motivate and encourage them, care for them, understand them, recognize their efforts, adjust their lesson, are smiling, have perseverance, are cooperative, polite and have zeal. In contrast, features in the behavior of teachers that repel students are: indifference, irony, reluctance, monotony and the stressful/pressing behavior. Such were the findings of other studies in evening schools. In the survey of Zounta (2013), "the adult students feel that teachers recognize and treat them as adults, understand their needs and cooperate effectively with them, they are interested, they reward, encourage, are patient, there is a personal connection and relationship between them, they are role models ..."

In the research of Fili (2012) in Evening Technical High Schools, the interviewees adults students express favorable comments about their teachers, as they encourage their students and they understand the obstacles which are encountered during the educational process. There is a significant difference between the views of the two age groups in relation to questions concerning: $i)$ whether the teachers understand that students have increased obligations and limited available time and ii) if they treat students equally. The older students have better communication with their teachers, because they usually participate in the course, they perform activities willingly, they are more organized in the classroom (carry a notebook, book, pen) and generally show more interest in lessons than the younger students, as they are more conscious about what they do. Additionally, older students have increased professional and family obligations that force them to make many absences. The teachers in order to help them complete their studies usually show some flexibility in their late attendance in class or give higher oral degrees to increase the limit of their absences. According to Tsikalaki (2007) these 
favorable educational interventions to older students trouble some younger students who do not enjoy the same privileges, so there is a sense of unequal treatment.The use of Information and Communications Technology is relatively small during the educational process in evening schools, but certainly greater than wahat was observed in the research of Tsikalaki (2007), where "only one professor of the fifteen that we met told us that he was using computers in courses in the workshop, (if there was a computer) and during the theory he remained in the traditional teaching with the blackboard". The reasons for this finding are: the reduced teaching time in the evening (20-40 minutes), which complicates the process of moving to the computer laboratory, setup the equipment, load the educational material, the question of the availability of the computer laboratory and modern technological equipment (projectors, laptops), and further the readiness and willingness of teachers to use Information and Communications Technology.

\section{Organization of the learning process}

A very large percentage (88.7\%) of the age group $25+$ agree that they are given opportunities to actively participate in the learning process. The corresponding rate for the age group 18 to 24 is $70.4 \%$, but the people in this group say at a rate of $66.6 \%$ that they would like to have more active participation in the course. Both age groups say they would like more encouragement from their teachers to participate in the course at the rate of $59.7 \%$ for the $25+$ group and $51.8 \%$ for the group 18-24. Rogers (1999) notes that the students will not learn unless they are active in the course of their learning, firstly on grounds of incitement because they need to achieve something and maintain a sense of success and secondly to promote learning, i.e. on the proposal, accepting and internalizing of the learning changes.

The most common use of the computers in the process of learning in classes of evening schools is desired by quite a large percentage of the students (65.6\% of the $25+$ group, and $51.8 \%$ of group 18 to 24 ). Hill (2001) argues that the intake of multiple experiences helps and activates learning. Learning is activated by creating different pathways in the brain during the conquest of new material. The brain operates on multiple levels in a coordinated way. This ability can be applied in the classroom where the learning process and the memory are induced by experiences. For many teachers Information and Communications Technologies are welcome, as they support and encourage the constructivist learning. This means that they will complement and expand the existing practices because they contain more interactive and self-directed uses that encourage students to act and to build new ideas and concepts and, thereby, transform the existing knowledge (Selwyn et al., 2006). Less than half of students (40.9\%) want to make the lesson more slowly. This percentage is much higher than the $24.7 \%$ of students who agreed that teachers have the stress of following and completing the curriculum leading to fast pace in learning. According to Rogers (1999), the active learning methods have a slow pace, while the topics can be completed faster with methods like the presentation, wherein the students watch or listen. However, the teacher cannot be certain that the students understood what the teacher wanted. The goal of the course should be to learn and not complete as many chapters as possible. However, speed seems to be important in the learning process and at evening high schools, due to the tight timetable imposed by the curriculum and the focus on the national examinations.

$40.2 \%$ of students would like more questions from their teachers. $6.7 \%$ of the $25+$ age group (compared with $29.6 \%$ of the younger age group) would prefer less memorizing as learning is not a matter of mechanical memorization processes, events, or concepts, but a complicated process of finding solutions, skills training and creating correlations (Rogers, 1999). As for working in groups, $69.3 \%$ of the $25+$ age group and $59.2 \%$ of the age group 18 to 24 agree that they are given opportunities to work in groups with their peers, while $54.6 \%$ of students would welcome more cooperation in groups. Working in groups facilitate both a better understanding of the course $(73.5 \%)$, and the development of communication and cooperation among students $(88.6 \%$ of the age group $25+$ and $70.3 \%$ of the age group 18-24). A small percentage of students (19.3\%) agrees that the creation of groups in the classroom results in noise and distraction, while $36.1 \%$ of the $25+$ age group and $22.2 \%$ of the age group 18 to 24 agree that the creation of groups is impractical because of the indifference of many students.According to Kokkos (1999) working in groups is considered by many researchers as the cornerstone of adult education. Data reveal that working in groups is applied satisfactorily and the majority of students show satisfied from both the learning outcomes and the communication and cooperation they have. Critical factor for the functionality of the group is the disparity between the members which is greater at evening schools (in terms of age, gender, cultural background, profession, personality, educational goals etc.). Therefore, the good climate shaped by the good relations between the group's members is determinant for the cohesion of the team. The better the climate, the more heterogeneity that the group can withstand (Polemi-Todoulou, 2012).Regarding the difficulties in understanding a course they are the following: the previous gaps in knowledge (75.8\% of the age group 25+), what they learn is at odds with those who believed (32.3\% of the age group $25+$ and $22.2 \%$ of the age group 18 to 24 ), the nature of the course (46.1\%), the memorization of concepts (51.6\% of the $25+$ group), the obscure books ( $43.2 \%$ ), not related to their interests and experiences (35.2\%), the noise in class (34.4\% of the $25+$ group and $29.6 \%$ of group 18 to 24$)$. 


\section{Conclusions}

According to Mpikos (2007), the climate of the classroom is affected by the teacher, the school, the personality of the students and the quality of relationships that exist within it. The student role has two different complementary aspects: The first relates to the student's relationship with the others and the learning that is built from this interaction (social learning), and the second concerns the content of the curriculum and the learning that results from the contact with it through the relationships developed with the teacher and classmates. In evening schools there is diversity of age and the differences that entail, like maturity, experience, educational goals, professional and family obligations. These differences seem to cause embarrassment and wariness between older and younger students but subside as time passes. The impact of the older students in the learning environment in their classroom as shown by the responses $(70 \%$ agree that the younger students benefit from coexistence with the older) is catalytic. The respect, interest and willingness to cooperate in the learning process, positively affect younger students towards this direction. Therefore, older pupils should be used by the teacher in order to create a good and cooperative class climate. Furthermore, the relationships of older student with their teachers are equal, and it appears that the first (as reflected by their answers) respect the latter. As pointed out by Rogers (1999: 307) «Perhaps the greatest reward in the evaluation of adult learning are those signs of satisfaction that many adults express during their relationships with their teachers. Students are ultimately the best judges of whether they take what they feel that they need".

Regarding if the adult students would suggest the evening school to an adult who has not finished high school, the vast majority responded positively $(72.2 \%$ completely agree and $15.6 \%$ agree). In correlation with the question of the first section where $46.7 \%$ agree that they learned about the evening school from previous students, we notice that the best way to promote the evening schools are the benefits arising from the attendance to. Despite the lack of teacher training in adult education, teachers of evening high schools seem to understand the basic principles, based on empathy and experience. "Empathy includes creating relationship, overcoming egocentricity by the teachers and their involvement with the real feelings of the student" (Zergiotis, 2007: 237). Beyond all this we consider it imperative to develop and implement training programs for teachers who teach in evening schools on issues related to the practice of adult education. These will enable teachers of evening schools to improve their knowledge on the following topics:

- communication-interpersonal relations. The ability to communicate is inherent in every human being, but the techniques and skills needed to make it more effective in different circumstances, can be the subject of learning for any person and at any age (Zergiotis, 2007).

- active-participative methods of teaching.

- group dynamics and requirements of the working groups. The teacher can proceed with proper handling, to bring a balance between the opposing forces that contribute to the breakdown of cohesion. The consistency in the class group is important to improve its performance.

Moreover, the reform of curricula is necessary and textbooks should take into account the knowledge level of the students and that they may be used by adult students who return to school after an absence of several years. The importance of the implementation of the practices that will improve the learning climate in the school classes is noted by Karapostolis (2011: 208), “... what is left of the peaceful disposition for understanding te what happens in the world is within classrooms and auditoriums. Only there different opinions can be expressed and considered without interference of material interest. Only there, no matter how many imperfections there are, there is no deliberate deception".

Greek

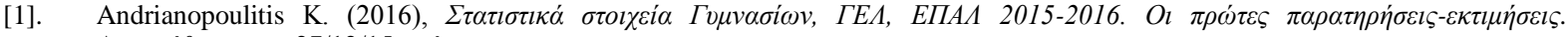

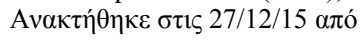

[2]. https://www.alfavita.gr/arthron/statistika-stoiheia-gymnasion-gel-epal-2015-2016-oi-protes-paratiriseis-ektimiseis

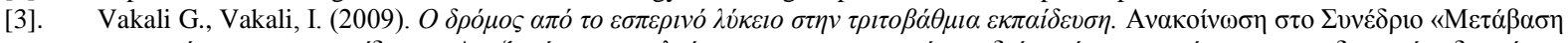

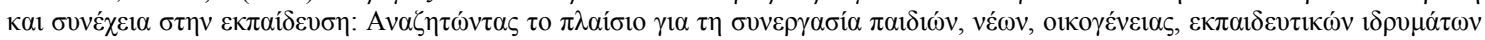

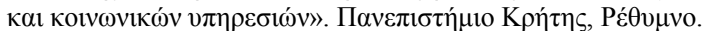

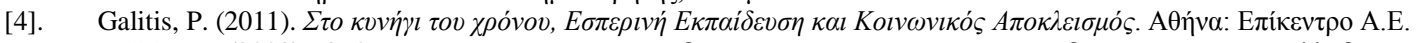

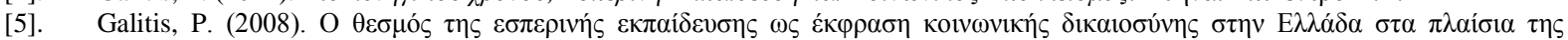

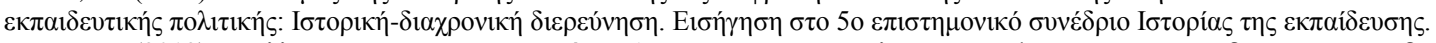

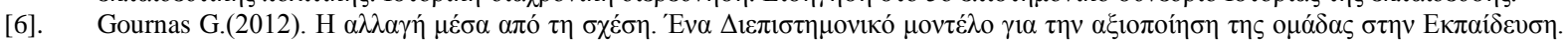

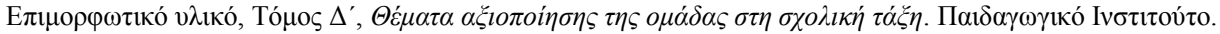

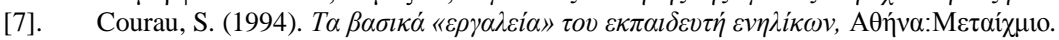

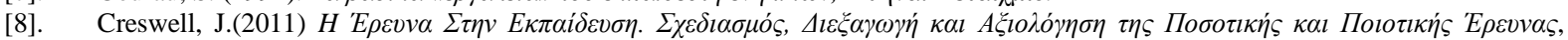
$\mathrm{A} \theta \eta \dot{v} v \alpha, \varepsilon \kappa \delta . \mathrm{E} \Lambda \Lambda \mathrm{HN}$.

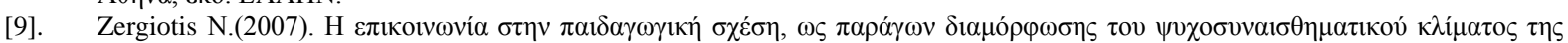

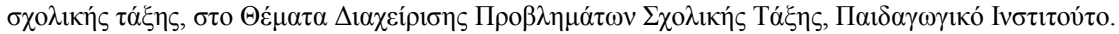

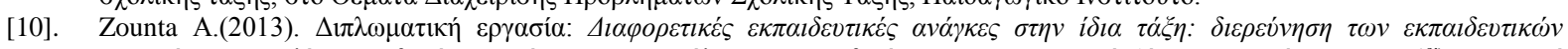

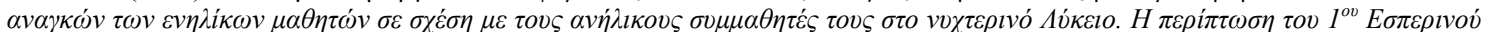

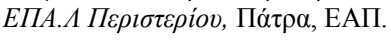




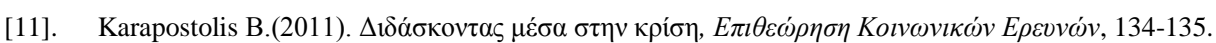

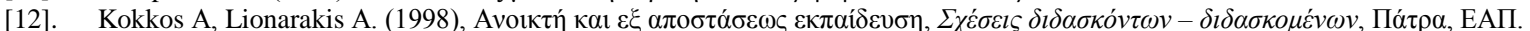

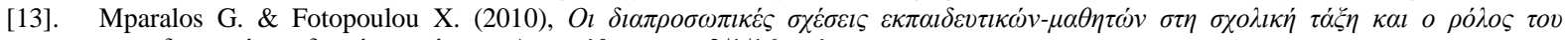

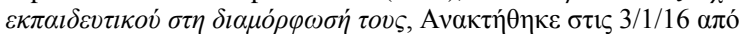

[14]. https://filologostpe.files.wordpress.com/2012/02/ceb4ceb9ceb1cf80cf81cebfcf83cf89cf80ceb9cebaceadcf82cf83cf87ceadcf83ceb5c eb9cf82-ceb5cebacf80ceb1ceb9ceb4ceb5cf85cf84ceb9cebacf8ecebd.pdf

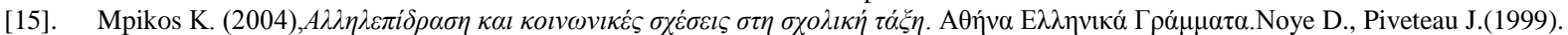

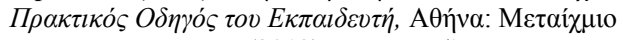

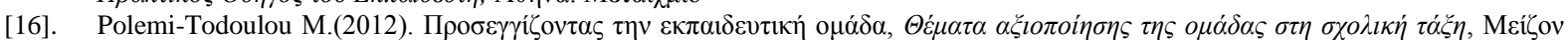

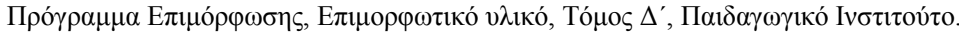

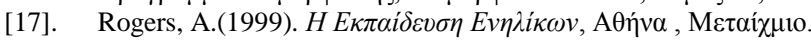

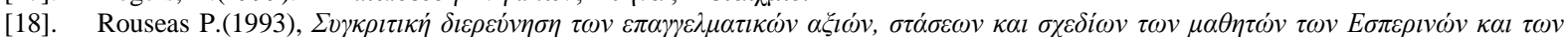

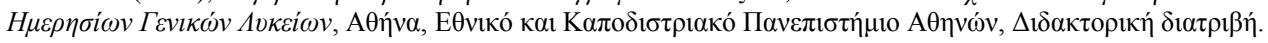

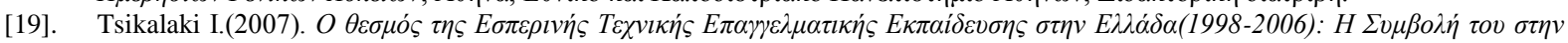

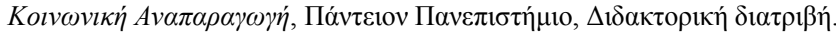

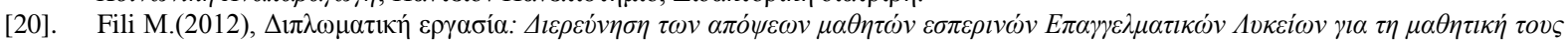

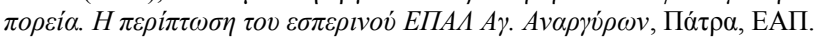

\section{English}

[21]. Boud D \& Walker D.(1994), Experience and Learning: Reflection at Work. Deakin University, National Library of Australia.

[22]. Dirkx J. (2001). The Power of Feelings: Emotion, Imagination, and the Construction of Meaning in Adult Learning. The new update on adult learning theory. New Directions for Adult and Continuing Education, no89, Spr 2001

[23]. Hill L.(2001). The Brain and Consciousness: Sourses of Information for Understanding Adult Learning. The new update on adult learning theory. New Directions for Adult and Continuing Education, no89, Spr 2001.

[24]. Illeris, K.(2009). Contemporary Theories of Learning. Learning theorists...in their own words. Routledge, London and New York.

[25]. Selwyn, N. , Gorard, S. ,Furlong J.(2006). Adult Learning in the Digital Age: Information Technology and the Learning Society, Routledge.

[26]. Tennant, M.(1997). Psychology and Adult Learning( $2^{\text {nd }}$ edition). Routledge, London and New York. 